\title{
Recurrent urinary infections in general practice
}

R. N. GRUNEBERG ${ }^{1}$

From the Department of Bacteriology, Edgware General Hospital, Edgware, Middlesex

SYNOPSIS Repeated episodes of acute, symptomatic urinary tract infections in domiciliary patients have been shown to be due to reinfection in $71 \%$ of instances and to recrudescence of $\supset$ the original infection in $29 \%$. Fresh episodes occurring at intervals of less than eight weeks from the original infection were due to reinfection or to recrudescence of infection in $\vec{\varphi}$ roughly equal numbers but those at intervals of eight weeks or more were due to reinfection. $\stackrel{ }{\odot}$

A major problem in the management of acute symptomatic urinary tract infection is that of the patient who returns at intervals with further episodes of infection despite initial cure. There is little information available on the nature of such repeated episodes of infection. Two possibilities exist: first, that the new infection represents a recurrence of the original infection, due to failure to eradicate the original organism or, second, that the new episode represents a fresh infection with another organism. Both situations are known to occur. For reasons discussed elsewhere (Grüneberg, Leigh, and Brumfitt, 1968) this distinction is fundamental in the proper management of the patient.

In the hospital situation reinfection is often apparent because the bacterial genus changes. However, in general practice, recurrent infections are very commonly due to Esch. coli and distinction is only possible by means of serotyping. The present report concerns an investigation in general practice to determine the relative importance of relapse and reinfection in recurrent infections.

\section{Methods}

Arrangements were made with a number of 'Present address: Department of Bacteriology, University College Hospital, London, WC1

Received for publication 25 February 1969. general practitioners to refer patients with acute⿳亠二口犬 urinary symptoms to the author. Such patients were usually seen within a few hours of attending $\varrho$ the surgery. A standard questionnaire with $\overrightarrow{\vec{O}^{\prime}}$ details of symptoms and previous history was 3 completed for each patient. A clean-catch urine? sample was collected after vulval or penile? cleansing with sterile distilled water and re-o응 frigerated until cultured. A seven-day course of chemotherapy was given, usually with a sul- 3 . phonamide or ampicillin, and the patient wasi asked to return in two weeks and again in six weeks for follow up. At the follow-up visit the urine was again examined. If the infection had cleared on both follow-up examinations the patient was discharged, but asked to come again if symptoms recurred. If the urinary infection 0 had not been eradicated further treatment wasi given. Patients returning with further episodes of infection were treated for these in the same way $\sigma$ as for the original infections. No attempt was made to detect subsequent episodes of asymptomatic bacteriuria in these patients. Only those patients who had a sterile urine between isolates or in whom the urinary organism changed without ${ }_{0}^{-}$ an intermediate sterile urine are included in this report. Those patients who failed to respond to $\frac{?}{\mathbb{D}}$ treatment and retained the original organism throughout are excluded.

The urines were cultured by a surface viable counting technique. Significant bacteriuria was? considered to exist if an organism was present in pure growth in numbers exceeding 100,000 per? 
millilitre urine. Organisms were identified by standard bacteriological methods. Strains of Esch. coli were serotyped by a tube agglutination method using specific antisera prepared in rabbits against the $O$ (somatic) antigens of Esch. coli.

\section{Results}

The results of identification of urinary organisms in 34 instances of repeated urinary infections are shown in Table I. Of the 68 infections, 46 (68\%) were due to Esch. coli.

Study of columns 1 and 2 (Table I) shows that in some cases the same organism was responsible for both the first and second infection, whereas in others reinfection was by a different organism. These findings are summarized in column 3 (Table I) as similar (S) or different (D) organisms. In most instances the reasons for this classification are clear. In four patients (marked in Table I) the urinary organisms on both occasions were Proteus mirabilis. The organisms were classified in these four patients on the basis of testing by Dienes' phenomenon of inhibition of swarming

\begin{tabular}{|c|c|c|c|}
\hline First Urinary Infection & Second Urinary Infection & $\begin{array}{l}\text { Organisms } \\
\text { Similar }(S) \text { or } \\
\text { Different }(D)\end{array}$ & $\begin{array}{l}\text { Interval } \\
\text { between } \\
\text { Infections } \\
\text { (weeks) }\end{array}$ \\
\hline $01^{1}$ & 04 & D & 12 \\
\hline Proteus mirabilis & Proteus mirabilis & $\mathrm{D}^{2}$ & 50 \\
\hline Proteus mirabilis & Proteus mirabilis & $\mathbf{S}^{2}$ & 4 \\
\hline 033 & 033 & $\mathbf{S}$ & 6 \\
\hline 06 & 075 & $\overline{\mathbf{D}}$ & 62 \\
\hline 048 & Proteus mirabilis & D & 38 \\
\hline 075 & 04 & $\bar{D}$ & 19 \\
\hline 039 & 02 & D & 6 \\
\hline 075 & 075 & $\mathbf{S}$ & 6 \\
\hline 075 & 011 & D & 28 \\
\hline 07 & 07 & $\mathbf{S}$ & 6 \\
\hline Untypable (rough) & Streptococcus faecalis & D & 4 \\
\hline Streptococcus faecalis & Klebsiella aerogenes & $\mathbf{D}$ & 2 \\
\hline Klebsiella aerogenes & Proteus mirabilis & $\mathbf{D}$ & 2 \\
\hline Proteus mirabilis & Proteus mirabilis & $\mathbf{S}^{2}$ & 6 \\
\hline 06 & 06 & $\mathbf{S}$ & 6 \\
\hline 06 & 06 & $\mathbf{S}$ & 7 \\
\hline Proteus mirabilis & Proteus mirabilis & $\mathrm{D}^{2}$ & 35 \\
\hline 06 & 06 & $\mathbf{S}$ & 5 \\
\hline 075 & 075 & $\mathbf{S}$ & 3 \\
\hline 025 & 075 & D & 8 \\
\hline 075 & Klebsiella aerogenes & D & 2 \\
\hline Klebsiella aerogenes & 075 & $\mathbf{D}$ & 4 \\
\hline Proteus mirabilis & 02 & D & 15 \\
\hline 075 & 075 & $\mathbf{S}$ & 7 \\
\hline Klebsiella aerogenes & 06 & D & 7 \\
\hline 06 & Untypable (smooth) & $\mathbf{D}$ & 5 \\
\hline 039 & 086 & D & 13 \\
\hline 0123 & 011 & D & 5 \\
\hline 01 & Untypable (smooth) & $\bar{D}$ & 13 \\
\hline Untypable (smooth) & Untypable (smooth) & $\mathbf{S}$ & 20 \\
\hline Staphylococcus albus & 04 & $\mathbf{D}$ & 2 \\
\hline 083 & Staphylococcus albus & D & 22 \\
\hline Atypical Proteus mirabilis & Atypical Proteus mirabilis & $\mathbf{S}$ & 4 \\
\hline
\end{tabular}

Table I A comparison of urinary organisms in initial and subsequent urinary infections

${ }^{1}$ Throughout this table the symbols 01,02 , etc, refer to the serotype of Esch. coli.

${ }^{2}$ In these cases the infecting organism was Proteus mirabilis on both occasions. and by the antibiotic sensitivity pattern. In $\mathrm{a}_{\bigcirc}^{c}$ further case both organisms were untypable $\overline{\bar{J}}$. smooth Esch. coli of the same $\mathrm{H}$ antigen type 0 (Hl) and similar antibiotic sensitivity pattern, $\stackrel{0}{=}$ and these have been regarded as being similaro organisms. A sixth doubtful instance is the organism shown in Table I as an atypical Proteus mirabilis. This was such a characteristic organismo that there can be very little uncertainty involved흠 in regarding these strains as similar.

Taking all 34 instances into account, 12 of the subsequent infections were caused by the organ $\frac{0}{\omega}$ ism isolated from the first infection, and $22 \rightarrow$ infections were caused by a different organism: from that originally isolated. If the six instances $\vec{\omega}$ where some doubt exists are excluded, eight of? the remaining 28 subsequent infections weres caused by the original organism and 20 byin different organisms.

The average interval between the first andi second infections in all 34 instances was 12.80 weeks. When the two infections were caused bys the same organism the average interval was $6.8-$ weeks (or 5.8 weeks if the four doubtful instances in this group are excluded), whereas when thetwo infections were caused by different organisms the average interval was 16.1 weeks (or 12.20 weeks if the two doubtful instances in this group are excluded). These results are presented ino Table II.

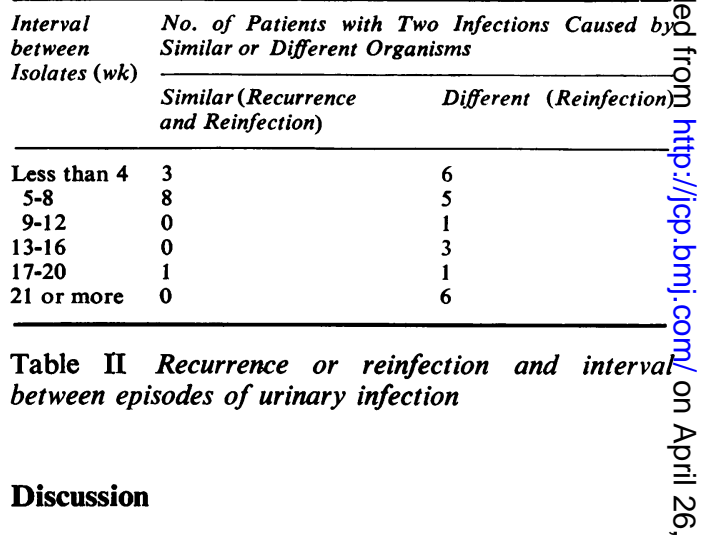

In hospital patients with urinary infection the $\tilde{}$ differentiation between recurrence and reinfection $N_{\omega}$ is often not difficult because the genus of the infecting organism in repeated infections ofteno changes. In general practice, however, the situation is more difficult since Escherichia coli $\stackrel{\text { ? }}{\text { ? }}$ is responsible for a large majority of all urinaryo infections $(68 \%$ in this series). Consequently, differentiation depends on the use of serological ${ }^{\mathbb{Q}}$ identification of strains of this organism.

Of the 34 episodes of repeated symptomatico urinary tract infection in domiciliary patients, the second infection was caused by a new organismo in 22 instances $(65 \%)$ and by the same organism in 12 instances (35\%) (Table I). This finding mayo를 require modification in two respects. 
First, in six patients the categorization of the organisms in the two infections as being similar or different cannot be regarded as being as secure as in the other 28. However, even if these six patients are excluded, the second infection was caused by a new organism in 20 patients $(71 \%)$ and by the original organism in eight patients $(29 \%)$.

Secondly, finding the same organism in the urine in two successive infections does not necessarily mean a recrudescence of a partially suppressed infection; it could also be a reinfection with a similar organism. This is made more possible since it has been shown that the urinary organism can nearly always be demonstrated in the faeces of domiciliary patients, and that while antibiotic treatment may eradicate the organism from the urine, it usually does not eradicate it from the faeces (Grüneberg et al, 1968). Consequently, the demonstration that $29-35 \%$ of renewed urinary infections are apparently due to recrudescence of infection rather than to reinfection may be an overestimate of the true frequency of recrudescence.

The finding that at least $67-71 \%$ of repeated infections in domiciliary practice are caused by infection with new organisms compares with incidences in hospital patients of $43 \%$ reported by Vosti, Goldberg, and Rantz in 1965 and $56 \%$ reported by McGeachie in 1966. (Both series concern only Esch. coli infections rather than the whole range of infections occurring in their patients.) Pryles and Glagovsky (1965) reported an incidence of $86 \%$ of different serotypes of Esch. coli in their series of 28 children with repeated episodes of urinary infection.

In spite of the importance of differentiating between reinfection and recurrence of infection in planning treatment (Grüneberg et al, 1968), serological identification of Escherichia coli strains is only of practical value to the patient when repeated infections are caused by this organism.

As might be expected, the average intervals between the two episodes of infection in the present series were 16.1 weeks in cases of reinfection (different organisms) and 6.8 weeks in cases of recrudescence of infection (similar organisms). If the six patients where some doubt exists are excluded, the intervals were $12 \cdot 2$ weeks and 5.8 weeks. If further infections occurring up to and including the seventh week from the initial infection are considered separately, 10 were caused by a different organism and 11 by a similar organism (Table II). Among infections occurring at intervals after the initial infection of eight weeks or more, 12 were caused by a new organism and only one by a similar infection. If the doubtful instances are again excluded, of the 18 infections occurring before the eighth week after the initial episode, 10 were due to reinfections and eight to recrudescence, whereas of the 10 episodes occurring at intervals of eight weeks or more, all were due to reinfection. $\subset$

McGeachie (1966) found an incidence of $\varrho$ reinfection of $67 \%$ in his series of 108 repeated Esch. coli urinary infections in hospital patients with such diverse conditions as glomerulonephritis, acute tubular necrosis, Kimmelstiel- Wilson kidneys, and multiple sclerosis, as judged $\stackrel{\vec{F}}{\vec{P}}$ by serological means. He further found an increase in the percentage of reinfections with the pas-듬 sage of time.

The findings reported here make it clear that while new episodes of urinary infection occurring $\frac{\varrho}{\mathscr{Q}}$ up to seven weeks after a previous urinary infection may be due to reinfection or to $\vec{O}$ recrudescence of the original infection, infections $\overrightarrow{-}$ occurring at intervals of eight weeks or more will $\omega_{\sigma}$ nearly always be due to reinfection in patients given short courses of chemotherapy.

Brown, Browder, Turck, and Petersdorf (1961) observed nine cases of replacement of the infect- $\omega$ ing urinary organism by a different organism during antibiotic therapy, and noted that the newo organisms were far more resistant to antibiotics? than the original organisms. Since the present $\vec{D}$ findings show that renewed infections occurring을. after two months are due to reinfection, and $\overrightarrow{\vec{\theta}}$ Brown et al have shown that reinfection during antibiotic therapy is due to organisms resistant. to antibiotics, prolonging the antibiotic treatment? of acute symptomatic urinary infections beyond two months is unlikely to be useful and may even be harmful, were it not probable that some of the

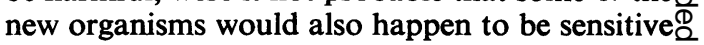
to the original antibiotic. In any case, the claims $\vec{\Rightarrow}$ sometimes made that the use of particular 3 antibiotics in short courses reduces the incidence? of further episodes of urinary infection shouldo be treated with some reserve since most such infections appear not to be due to the originalo organism.

I am indebted to the general practitioners in theo Edgware district for referring patients to me. It is $₹$ a pleasure to acknowledge the encouragement of $\mathrm{Dr}$ W. Brumfitt. The work was made possible by $\mathrm{a}_{\square}$ clinical research grant by the North West Metro-O을. politan Regional Hospital Board.

\section{References}

Brown, N. K., Browder, A. A., Turck, M., and Petersdorf, R. G.ర (1962). Treatment of persistent bacteriuria with a sixweek course of antibiotic therapy. Antimicrob. Agent 5 Chemother., 1, 324-333.

Grüneberg, R. N., Leigh, D. A., and Brumfitt, W. (1968). Escherichia coli serotypes in urinary tract infection:"
studies in domiciliary, ante-natal and hospital practice. In Urinary Tract Infection, pp. 68-79, edited by F. O'GradyO and W. Brumfitt. Oxford University Press, London.

McGeachie, J. (1966). Recurrent infections of the urinary tract: reinfection or recrudescence? Brit. med. J., 1, 952-954.

Pryles, C. V., and Glagovsky, A. (1965). Serological characterisation of Esch. coli: study in acute and recurrent urinary tract infections in infants and children. Pediatrics, 36 tract infections in infants and children. Pediatrics, ${ }^{36}$. $19-224$.
K.

Vosti, K. L., Goldberg, L. M., and Rantz, L. A. (1965). Host parasite interaction among infections caused by Escherichia E. H. Kass. Davis, Philadelphia. 